\title{
Analisis Vegetasi Hutan Kerangas Di Arboterum Nyaru Menteng Kalimantan Tengah
}

\author{
Sari Aulia Azizah ${ }^{1^{*}}$, Kissinger $^{2}$, Yusanto Nugroho ${ }^{3}$, Hamdani Fauzi $^{4}$ \\ ${ }^{1}$ Program Studi Pengelolaan Sumberdaya Alam \& Lingkungan, \\ Program Pascasarjana Universitas Lambung Mangkurat, Banjarmasin-Kalimantan Selatan \\ ${ }^{2,3,4}$ Universitas Lambung Mangkurat, Banjarmasin-Kalimantan Selatan \\ *Koresponden email : aauliaasari@gmail.com
}

Diterima : 15 Desember 2019

Disetujui : 17 Desember 2019

\begin{abstract}
Environmental management in the Nyaru Menteng Arboretum Conservation area especially for the Kerangas forest has not been done much. This research was conducted to determine the analysis of vegetation in the Kerangas forest in the Arboretum conservation area. This research is expected to get the value of vegetation and important value index in the Kerangas forest, based on the results of the study there are 23 types of vegetation found at seedling level, 24 types of vegetation found at sapling level, 14 types of vegetation found on poles, 13 types of vegetation found at tree. Blumeodendron tokbrai vegetation has the highest value with a NIP value of 18,047 at the seedling level. Vegetation type Litsea $s p$. Has the highest value with a NIP value of 18,159 at the stake level. The vegetation type Syzygium lineatum, has the highest value with a NIP value of 44,584 at the pole level. Vegetation type Cratoxylon glaucum, has the highest value with a NIP value of 48,656 at the tree level.
\end{abstract}

Keywords : Vegetation Analysis, Kerangas Forest, INP, Species Diversity, Nyaru Menteng

\begin{abstract}
Pengelolaan lingkungan pada kawasan Konservasi Arboretum Nyaru Menteng khususnya untuk hutan Kerangas belum banyak dilakukan. Penelitian ini dilakukan untuk mengetahui analisis vegetasi di hutan Kerangas yang ada di kawasan konservasi Arboretum. Penelitian ini diharapkan mendapatkan nilai vegetasi dan indeks nilai penting pada hutan Kerangas, berdasarkan hasil penelitian terdapat 23 jenis vegetasi yang ditemukan pada tingkat semai, 24 jenis vegetasi yang ditemukan pada tingkat pancang, 14 jenis vegetasi yang ditemukan pada tiang, 13 jenis vegetasi yang ditemukan pada pohon. Jenis vegetasi Blumeodendron tokbrai memiliki nilai tertinggi dengan nilai NIP 18.047 pada tingkat semai. Jenis vegetasi (Litsea sp.) memiliki nilai tertinggi dengan nilai NIP 18.159 pada tingkat pancang. Jenis vegetasi Syzygium lineatum, memiliki nilai tertinggi dengan nilai NIP 44.584 pada tingkat tiang. Jenis vegetasi Cratoxylon glaucum, memiliki nilai tertinggi dengan nilai NIP 48.656 pada tingkat pohon.
\end{abstract}

Keyword : Analisis Vegetasi, Hutan Kerangas, INP, Keanekaragaman Jenis, Nyaru Menteng

\section{Pendahuluan}

Hutan Kerangas merupakan suatu komunitas vegetasi yang berkembang pada kondisi tapak yang terbatas sangat mudah terdegradasi. Jika hutan ini sekali mengalami degradasi, maka akan berkembang menjadi savana terbuka yang disebut sebagai "Padang" [1]. Sekarang keberadaan hutan Kerangas dinilai sangat penting, karena berfungsi untuk melindungi tumbuhan lain kemudian diambil kayunya. Kerusakan dan terdegradasinya hutan Kerangas tersebut disebabkan kurang pedulinya masyarakat, pemerintah, dan pihak berwenang terhadap kelestarian hutan Kerangas. Pemicu yang ditumbulkan dari kekurangpedulian tersebut salah satunya disebabkan oleh kekurangmampuan dalam mengeksplorasi pemanfaatan optimal dari hutan Kerangas. Sedangkan di Kalimantan Tengah salah satu hutan Kerangas yang berpontensi memiliki diversitas dan cadangan karbon yaitu kawasan Konservasi Arboretum Nyaru Menteng.

Permasalahan yang terjadi saat ini adalah pengelolaan lingkungan pada kawasan Konservasi Arboretum Nyaru Menteng khususnya untuk hutan Kerangas belum banyak dilakukan. Hal ini dijelaskan dengan belum tersedianya data atau terbatasnya informasi mengenai potensi diversitas maupun cadangan karbon pada hutan Kerangas sebagai sumber pengelolaan lingkungan baik itu untuk pengurangan emisi 
karbon terutama dari kawasan konservasi. Kawasan Arboretum Nyaru Menteng merupakan kawasan camping pramuka dan tempat reintroduksi orangutan yang dilakukan oleh Yayasan Borneo Orangutan Survival Foundation (BOS). Pengelolaan kawasan Arboretum nyaru menteng saat ini berfokus pada pelestarian orang hutan serta kurangnya fokus dan program pelestarian pada kawasan hutan disekitar Arboretum Nyaru Menteng tersebut. Keterbatasan tersebut mengakibatkan upaya konservasi yang berbasiskan nilai manfaat berkelanjutan dari hutan Kerangas secara keseluruhan belum dapat dilakukan.

Penelitian ini dilakukan untuk mengetahui kerapatan, serta analisis vegetasi pada hutan Kerangas yang ada di kawasan konservasi Arboretum. Penelitian ini diharapkan mendapatkan nilai penting pada hutan Kerangas, berdasarkan analisis pada diversitas serta potensi simpanan karbon yang ada pada hutan Kerangas.

Kawasan hutan Kerangas memiliki peranan penting bagi kehidupan sekitar, terutama dalam perlindungan fungsi ekologi dan keanekaragaman hayati. Komposisi dan struktur vegetasi merupakan salah satu parameter yang harus diperhatikan dalam kegiatan pelestarian hutan. Salah satu upaya konservasi adalah melalui analisis vegetasi pohon pada hutan ekosistem. Penelitian ini diharapkan dapat diketahui berapa jenis vegetasi pohon pada masing-masing kelas vegetasi.

\section{Kerangka Teori}

Kerangas merupakan suatu istilah yang awalnya diberikan oleh suku Dayak Iban terhadap lahan yang berada di dataran rendah atau zona submontana yang dikarenakan kondisi tanahnya bila ditanami padi maka padinya tidak dapat tumbuh [2]. Vegetasi hutan Kerangas yang tumbuh juga terbatas dan memiliki karakter khusus akibat dari adaptasi terhadap lingkungan yang terbatas [1].

Hutan Kerangas didominasi oleh jenis pohon berukuran pendek dengan kanopi yang hanya memiliki satu lapisan saja. Hutan Kerangas dapat ditemukan dalam kawasan yang sangat luas di Kalimantan dan sedikit di Sumatera [3]. Komposisi spesies di hutan Kerangas Taman Nasional Danau Sentarum didominasi oleh tingkat pertumbuhan pancang dan sebagian besar anggota famili Dipterocarpaceae. Pada kondisi lantai hutan yang berpasir dan miskin hara, air hujan terserap dengan cepat sehingga kapasitas tumbuhan mengikat air di akar relatif kecil [4].

Hutan Kerangas memiliki karakteristik komposisi vegetasi yang khusus, pohon-pohon tampak pendek dan kurus-kurus berbeda dengan hutan campuran dataran rendah pada umumnya [5].Tumbuhan di hutan Kerangas teradaptasi secara fisiologis yaitu dengan adaptasi morfologi vegetasi hutan Kerangas yang kecil dan seragam, daun yang berkilat dan kecil-kecil, ini untuk mengurangi besarnya penguapan [5].

Analisis vegetasi merupakan analisis yang digunakan untuk mengetahui jenis-jenis tumbuhan dan menetapkan jenis yang dominan [6]. Analisa vegetasi dilakukan untuk mengetahui tingkat keragaman spesies, struktur poppulasi serta ekologi [7]. Analisis vegetasi diterapkan untuk memperoleh informasi kuntitatif tentang struct (data bentukan) dan data komposisi suatu komunitas tumbuhan [8].

Struktur vegetasi merupakan hasil penataan ruang oleh komponen penyusun tegakan dan bentuk hidup, stratifikasi dan penutupan vegetasi yang digambarkan melalui keadaan diameter, tinggi, penyebaran dalam ruang, keanekaragaman tajuk, serta kesinambungan jenis. Komposisi vegetasi berperan sebagai daftar floristik dari jenis vegetasi yang ada dalam suatu komunitas [9].

\section{Metodologi Penelitian}

Penelitian ini dilakukan di Hutan Kerangas Kawasan Konservasi Arboretum Nyaru Menteng, Palangka Raya - Kalimantan Tengah selama 3 bulan yaitu dari bulan April - Juni 2019. Pengambilan data primer dan sekunder dilakukan mulai dari kegiatan pengambilan sampel, analisis data, pengelohan data sampel penelitian serta pembuatan laporan tesis. Alat yang digunakan dalam pengambilan data primer adalah sebagai berikut : Global Position System (GPS), Pita Ukur, Kompas, Tali Rapia, Meteran, Alat Tulis, Tally sheet. Pengolahan data dilakukan menggunakan program Ms. Excel.

Jenis data yang dikumpulkan dalam penelitian ini adalah data dimensi pohon dan permudaan. Dimensi tegakan yang diukur adalah jumlah jenis dan diameter pohon dan tiang. Kegiatan pengambilan sampel menggunakan metode jalur berpetak. Pembuatan jalur pada areal yang diteliti dilakukan dengan cara purposive sampling. Jalur pengamatan yang dibuat sebanyak 4 jalur, masing-masing jalur terdiri dari 5 petak pengukuran. Jalur ini dibuat untuk pengukuran vegetasi pada lokasi penelitian. 
Dalam satu jalur pengamatan memiliki ukuran yaitu panjang jalur masing-masing 100 meter dengan lebar jalur 20 meter. Petak-petak ukur dibuat dalam setiap jalur penelitian dengan ukuran $20 \times 20$ meter untuk pengukuran pohon, sub petak ukuran $10 \times 10$ meter untuk pengamatan tingkat tiang, sub petak ukuran $5 \times 5$ meter untuk pengamatan tingkat pancang dan ukuran $2 \times 2$ meter untuk tingkat semai dan tumbuhan bawah. Pembuatan jalur berpetak untuk pengukuran analisis vegetasi dibedakan menurut kriteria tingkat pertumbuhannya dengan cara: 1) Tingkat semai dan tumbuhan bawah ukuran petaknya 2 $\mathrm{m} \times 2 \mathrm{~m}, 2$ ) Tingkat pancang ukuran petaknya $5 \mathrm{~m} \times 5 \mathrm{~m}, 3$ ) Tingkat tiang ukuran petaknya $10 \mathrm{~m} \times 10 \mathrm{~m}$, 4) Tingkat pohon ukuran petaknya $20 \mathrm{~m} \times 20 \mathrm{~m}$. Petak ukur yang dibuat di lokasi penelitian bisa dilihat pada Gambar 1.

\section{d. $20 \times 20$}

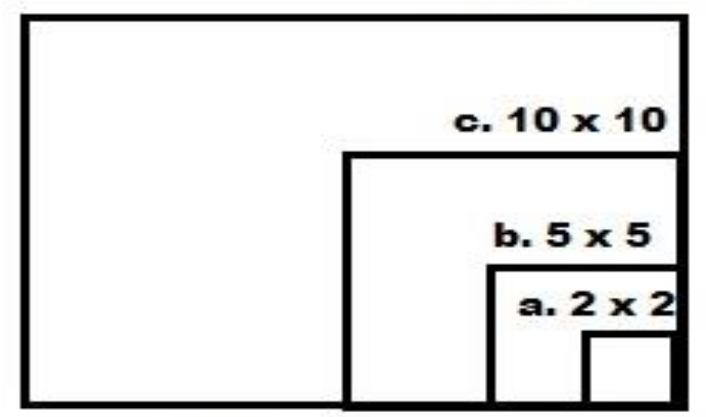

Gambar 1. Petak ukur penelitian

\section{Metode Analisis Data}

Berdasarkan data hasil analisis vegetasi diketahui kekayaan jenis di kawasan tersebut. Kemudian setiap jenis vegetasi dihitung Kerapatan (K), Kerapatan Relatif (KR), Frekuensi (F), Frekuensi Relatif (FR), Dominansi (D) dan Dominansi Relatif (DR) dengan rumus sebagai berikut [10] :

- Kerapatan Jenis (K) = Jumlah individu suatu jenis /Luas plot pengamatan

- Kerapatan Relatif (KR) = (Kerapatan suatu jenis/Kerapatan seluruh jenis) $\times 100 \%$

- Frekuensi Jenis $(F) \quad=$ Jumlah plot ditemukannya suatu jenis/Jumlah total plot pengamatan

- Frekuensi Relatif (FR) = (Frekuensi suatu jenis / Frekuensi seluruh jenis) $x 100 \%$

- Dominansi Jenis (D) = Luas bidang dasar suatu jenis / Luas plot pengamatan

- Dominansi Relatif $(D R)=($ Dominasi suatu jenis / Dominasi seluruh jenis $) \times 100 \%$

Selanjutnya dihitung nilai Indeks Nilai Penting (INP) untuk mengetahui jenis dan tingkat tumbuhan yang dominan. Analisis vegetasi secara kuantitatif dapat ditinjau dari beberapa parameter sebagai data dasar seperti kerapatan dan kerapatan relatif, frekuensi dan frekuensi relatif dominansi dan dominansi relatif dan NIP dengan rumus sebagai berikut [11]:

- Semai : INP $\quad=\mathrm{KR}+\mathrm{FR}$

- Pancang, Tiang, Pohon : INP = KR + FR + DR

\section{Hasil dan Pembahasan \\ Semai}

Beberapa jenis vegetasi tumbuhan yang terdapat pada lokasi penelitian dan dapat dilihat pada Tabel 1. Tabel ini menunjukkan bahwa lokasi penelitian di Hutan Kerangas Arboretum Nyaru Menteng INP tumbuhan sangat beragam. Jumlah vegetasi tumbuhan pada lokasi penelitian sebanyak 23 jenis tanaman dengan INP tertinggi yaitu pada jenis tanaman Kenari dan Bintagur dan terendah pada jenis Jejambuan dan Manggis. Sebagian tumbuhan berhasil tumbuh dalam kondisi lingkungan yang beraneka ragam sehingga tumbuhan tersebut cenderung tersebar luas [12]. 
Tabel 1. Jenis tingkat semai pada Nilai Indeks Penting (INP) di lokasi penelitian

\begin{tabular}{|c|c|c|c|c|c|c|}
\hline No & Jenis Tumbuhan & $\mathrm{K}$ & KR & $\mathrm{F}$ & FR & INP \\
\hline 1. & Agathis Agathis borneensis) & 20000 & 2.041 & 0.200 & 1.961 & 4.002 \\
\hline 2. & Bintan (Licania splendens) & 20000 & 2.041 & 0.200 & 1.961 & 4.002 \\
\hline 3. & Bintangur (Calophyllum hosei Ridi) & 100000 & 10.204 & 0.800 & 7.843 & 18.047 \\
\hline 4. & Belangiran (Shorea belangeran) & 62500 & 6.378 & 0.800 & 7.843 & 14.221 \\
\hline 5. & Ehang (Diospyros siamang Bakh) & 45000 & 4.592 & 0.400 & 3.922 & 8.513 \\
\hline 6. & Gerunggang (Cratoxylon glaucum) & 32500 & 3.316 & 0.600 & 5.882 & 9.199 \\
\hline 7. & Jejambuan (Syzygium sp.) & 2500 & 0.255 & 0.200 & 1.961 & 2.216 \\
\hline 8. & Kambasira (Ilex cymosa Blume) & 85000 & 8.673 & 0.400 & 3.922 & 12.595 \\
\hline 9. & Katiau (Madhuca motleyana) & 27500 & 2.806 & 0.200 & 1.961 & 4.767 \\
\hline 10. & Kapur Naga (Calophyllum inophyllum) & 12500 & 1.276 & 0.400 & 3.922 & 5.197 \\
\hline 11. & Kenari (Blumeodendron tokbrai (Blume) Kurz) & 120000 & 12.245 & 0.600 & 5.882 & 18.127 \\
\hline 12. & Kempas (Koompassia malaccensis Benth) & 25000 & 2.551 & 0.200 & 1.961 & 4.512 \\
\hline 13. & Kerandau (Blumeodendron tokbrai (Blume) Kurz) & 30000 & 3.061 & 0.600 & 5.882 & 8.944 \\
\hline 14. & Madang (Litsea sp.) & 5000 & 0.510 & 0.200 & 1.961 & 2.471 \\
\hline 15. & Mahang (Macaranga hosel King) & 7500 & 0.765 & 0.200 & 1.961 & 2.726 \\
\hline 16. & Makakang (Melastoma sp.) & 52500 & 5.357 & 0.800 & 7.843 & 13.200 \\
\hline 17. & Manggis (Garcinia cf.bancana) & 2500 & 0.255 & 0.200 & 1.961 & 2.216 \\
\hline 18. & Meranti (Shorea sp.) & 57500 & 5.867 & 0.800 & 7.843 & 13.710 \\
\hline 19. & Merapat (C. Rotundatus) & 100000 & 10.204 & 0.400 & 3.922 & 14.126 \\
\hline 20. & Palawan (Tristaniopsis sp.) & 95000 & 9.694 & 0.600 & 5.882 & 15.576 \\
\hline 21. & Punak (Tretramerista glabra Miq) & 65000 & 6.633 & 0.800 & 7.843 & 14.476 \\
\hline 22. & Simpur (Dillenia indica) & 5000 & 0.510 & 0.400 & 3.922 & 4.432 \\
\hline 23. & Tarantang (Campnosperma coriaceum) & 7500 & 0.765 & 0.200 & 1.961 & 2.726 \\
\hline & Jumlah & 980000 & 100 & 10.2 & 100 & 200 \\
\hline \multicolumn{7}{|c|}{ Keterangan: } \\
\hline \multicolumn{7}{|c|}{$\mathrm{K} \quad$ : Kerapatan $(\mathrm{K})$} \\
\hline \multicolumn{7}{|c|}{ KR $\quad$ : Kerapatan Keralif (KR) } \\
\hline \multicolumn{7}{|c|}{$\mathrm{F} \quad:$ Frekuensi $(\mathrm{F})$} \\
\hline \multicolumn{7}{|c|}{ FR $\quad$ : Frekuensi Relatif (FR) } \\
\hline \multicolumn{7}{|c|}{ INP $\quad$ : Indeks nilai penting (INP) } \\
\hline
\end{tabular}

Kerapatan relatif (KR) tertinggi pada jenis Kenari dan kerapatan terendah pada jenis Jejambuan. Tingginya nilai pada jenis Kenari karena mampunya beradaptasi terhadap lingkungan, selain itu rendahnya nilai pada jenis Manggis karena kurang mampunya tanaman beradaptasi terhadap lingkungan. Sebagian tumbuhan dapat berhasil tumbuh dalam kondisi lingkungan yang beraneka ragam sehingga tumbuhan tersebut cenderung tersebar luas [12].

Frekuensi relatif (FR) tertinggi pada jenis Makakang, Bintagur dan jenis lainnya, sedangkan nilai terendah Tarantang dan jenis lainnya. Jenis-jenis tersebut dapat beradaptasi dengan kondisi lingkungan tetapi banyak jenis lain yang tidak dapat beradaptasi dengan lingkungan sehingga rata-rata nilai yang didapat rendah [12]. Nilai indeks keanekaragaman rendah menunjukkan bahwa terdapat tekanan ekologi baik dari faktor biotik (persaingan antar individu tumbuhan) atau faktor abiotik [13]. Keanekaragaman rendah biasanya terdapat pada komunitas yang ada di daerah dengan lingkungan yang ekstrim seperti daerah kering dan tanah miskin. Penyebaran dan pertumbuhan individu pohon sangat dipengaruhi oleh daya tumbuh biji, topografi keadaan tanah dan faktor lingkungan lainnya. Biji pohon tersebar di daerah yang miskin bahan organik dan dengan intensitas cahaya yang berlebih.

\section{Pancang}

Beberapa jenis keanekaragaman vegetasi yang terdapat pada lokasi penelitian dan dapat dilihat pada Tabel 2 yang menunjukkan bahwa pada lokasi penelitian di Hutan Kerangas Arboretum Nyaru Menteng, INP tumbuhan sangat beragam. Jumlah keanekaragaman vegetasi pada lokasi penelitian seperti pada Tabel 2 sebanyak 24 jenis tumbuhan dengan nilai INP tertinggi pada jenis Simpur dan nilai terendah pada Bintagur, Belengeran dan jenis lainnya. 
Tabel 2. Jenis tingkat Pancang pada Nilai Indeks Penting (INP) di lokasi penelitian

\begin{tabular}{clccccr}
\hline No. & \multicolumn{1}{c}{ Jenis Tumbuhan } & $\mathrm{K}$ & $\mathrm{KR}$ & $\mathrm{F}$ & $\mathrm{FR}$ & \multicolumn{1}{c}{ INP } \\
\hline 1. & Bintagur (Calophyllum hosei Ridi) & 400 & 0.341 & 0.200 & 1.724 & 2.065 \\
2. & Belangaran (Shorea belangeran) & 400 & 0.341 & 0.200 & 1.724 & 2.065 \\
3. & Gandis (Garcinia sp) & 6400 & 5.461 & 1.000 & 8.621 & 14.081 \\
4. & Gerunggang (Cratoxylon glaucum) & 11200 & 9.556 & 0.800 & 6.897 & 16.453 \\
5. & Hangkang (Palaquium leiocarpum) & 4000 & 3.413 & 0.400 & 3.448 & 6.861 \\
6. & Jejambuan (Syzygium sp.) & 4800 & 4.096 & 0.800 & 6.897 & 10.992 \\
7. & Kambasira I(lex cymosa Blume) & 2400 & 2.048 & 0.200 & 1.724 & 3.772 \\
8. & Kapur Naga (Calophyllum inophyllum) & 800 & 0.683 & 0.200 & 1.724 & 2.407 \\
9. & Kempas (Koompassia malaccensis Benth) & 1600 & 1.365 & 0.400 & 3.448 & 4.813 \\
10. & Kenari (Blumeodendron tokbrai (Blume) Kurz) & 6000 & 5.119 & 0.400 & 3.448 & 8.568 \\
11. & Kerandau (Blumeodendron tokbrai (Blume) Kurz) & 8000 & 6.826 & 0.400 & 3.448 & 10.274 \\
12. & Ketapang (Terminalia catappa) & 400 & 0.341 & 0.200 & 1.724 & 2.065 \\
13. & Madang (Litsea sp.) & 13200 & 11.263 & 0.800 & 6.897 & 18.159 \\
14. & Mahang (Macaranga pruinosa (Miq.) Mull. Arg.) & 7200 & 6.143 & 0.800 & 6.897 & 13.040 \\
15. & Makakang (Melastoma sp) & 8000 & 6.826 & 0.800 & 6.897 & 13.722 \\
16. & Malam-Malam (Diospyros bantamemsis) & 2800 & 2.389 & 0.400 & 3.448 & 5.837 \\
17. & Manggis Hutan( Garcinia cf.bancana) & 1600 & 1.365 & 0.200 & 1.724 & 3.089 \\
18. & Meranti (Shorea sp.) & 9200 & 7.850 & 0.600 & 5.172 & 13.022 \\
19. & Palawan (Tristaniopsis sp.) & 9600 & 8.191 & 0.600 & 5.172 & 13.364 \\
20. & Punak (Tetramerista glabra) & 1200 & 1.024 & 0.400 & 3.448 & 4.472 \\
21. & Rambutan Hutan (Xrerospermum sp.) & 1600 & 1.365 & 0.200 & 1.724 & 3.089 \\
22. & Simpur (Dillenia indica) & 10000 & 8.532 & 1.000 & 8.621 & 17.153 \\
23. & Sukun Hutan (Artocarpus communis) & 6000 & 5.119 & 0.400 & 3.448 & 8.568 \\
24. & Terantang (Campnosperma coriaceum) & 400 & 0.341 & 0.200 & 1.724 & 2.065 \\
\hline & & 117200 & 100 & 12 & 100.000 & 200 \\
\hline
\end{tabular}

Keterangan:

K : Kerapatan (K)

KR : Kerapatan Keralif (KR)

F : Frekuensi (F)

FR : Frekuensi Relatif (FR)

INP : Indeks nilai penting (INP)

Kerapatan relatif (KR) tertinggi pada jenis pohon Madang dan kerapatan terendah pada jenis Bintagur dan jenis lainnya. Frekuensi Relatif (FR) dengan nilai tertinggi gandis dan simpur, sedangkan nilai terendah pada Bintagur dan jenis lainnya. Nilai-nilai dari karakteristik ekologi hutan Kerangas dihubungkan dengan pemanfaatan bioaktivitas maka terdapat peluang pemanfaatan berbagai jenis tumbuhan di hutan Kerangas. Potensi jenis, biomassa dan keberlanjutan regenerasi tercermin dari komposisi jenis dan nilai-nilai seperti dominansi relatif (DR), kerapatan relatif (KR), frekuensi relatif (FR) dan indeks nilai penting [14].

Tiang

Beberapa jenis vegetasi tumbuhan yang terdapat pada Hutan Kerangas Arboretum Nyaru Menteng dapat dilihat pada Tabel 3. Jumlah Keanekaragaman vegetasi yang ada pada lokasi penelitian sebanyak 14 jenis tumbuhan dengan nilai indeks penting (INP) yang mendominasi pada jenis Mahang dan Galam Tikus, dan nilai terendah yaitu Palawan Merah dan Tutup Kabali. Jenis dengan nilai INP $\geq 10 \%$ adalah jenis yang termasuk sebagai penyusun utama komunitas vegetasi di suatu kawasan[15]. Kerapatan Relatif (KR) dengan nilai tertinggi pada jenis pohon Galam Tikus dan nilai terendah pada Palawan Merah, Belangiran dan jenis lainnya. Frekuensi Relatif (FR) nilai tertinggi pada jenis Gerunggang, Kempas, Mahang dan jenis lainnya, sedangkan nilai terendah pada jenis pohon Belangeran, Jejambuan dan Palawan Merah. 
Tabel 3. Jenis tingkat Tiang pada Nilai Indeks Penting (INP) di lokasi penelitian

\begin{tabular}{clccccc}
\hline No. & \multicolumn{1}{c}{ Jenis Tumbuhan } & $\mathrm{K}$ & $\mathrm{KR}$ & $\mathrm{F}$ & $\mathrm{FR}$ & $\mathrm{INP}$ \\
\hline 1. & Belangeran (Shorea belangeran) & 100 & 0.714 & 0.200 & 3.030 & 8.699 \\
2. & Galam tikus (Syzygium lineatum) & 3500 & 25.000 & 0.600 & 9.091 & 44.584 \\
3. & Gambir (Platea sp.) & 700 & 5.000 & 0.400 & 6.061 & 17.650 \\
4. & Gandis (Garcinia sp) & 600 & 4.286 & 0.400 & 6.061 & 15.445 \\
5. & Gerunggang (Cratoxylon glaucum) & 2300 & 16.429 & 0.800 & 12.121 & 40.928 \\
6. & Jejambuan (Syzygium sp.) & 100 & 0.714 & 0.200 & 3.030 & 6.793 \\
7. & Kempas (Koompassia malaccensis Benth) & 1500 & 10.714 & 0.800 & 12.121 & 32.329 \\
8. & Madang (Litsea sp.) & 500 & 3.571 & 0.400 & 6.061 & 16.070 \\
9. & Mahang (Macaranga pruinosa (Miq.) Mull. Arg.) & 2500 & 17.857 & 0.800 & 12.121 & 44.279 \\
10. & Meranti (Shorea sp.) & 1400 & 10.000 & 0.800 & 12.121 & 33.870 \\
11. & Palawan Merah (Tristaniopsis sp.) & 100 & 0.714 & 0.200 & 3.030 & 5.576 \\
12. & Rahanjang (Xylopia fusca Maingay) & 300 & 2.143 & 0.400 & 6.061 & 14.024 \\
13. & Tumih (Combretocarpus rotundatus) & 300 & 2.143 & 0.400 & 6.061 & 13.206 \\
14. & Tutup kabali (Diospyros pseudomalabarica) & 100 & 0.714 & 0.200 & 3.030 & 6.548 \\
\hline & $\quad$ Jumlah & 14000 & 100 & 6.6 & 100.000 & 300 \\
\hline
\end{tabular}

Keterangan:

K : Kerapatan (K)

KR : Kerapatan Keralif (KR)

F : Frekuensi (F)

FR : Frekuensi Relatif (FR)

INP : Indeks nilai penting (INP)

\section{Pohon}

Variasi jenis vegetasi tumbuhan yang terdapat pada lokasi penelitian di Hutan Kerangas Arboretum Nyaru Menteng dapat dilihat pada Tabel 4, yang menunjukkan bahwa INP tumbuhan sangat beragam.

Tabel 4. Jenis tingkat pohon pada Nilai Indeks Penting (INP) di lokasi penelitian

\begin{tabular}{clccccc}
\hline No & \multicolumn{1}{c}{ Jenis Tumbuhan } & $\mathrm{K}$ & $\mathrm{KR}$ & $\mathrm{F}$ & $\mathrm{FR}$ & $\mathrm{INP}$ \\
\hline 1. & Belangiran (Shorea belangeran) & 175.000 & 3.465 & 0.400 & 6.061 & 12.692 \\
2. & Gandis (Garcinia sp) & 325.000 & 6.436 & 0.600 & 9.091 & 22.633 \\
3. & Gerunggang (Cratoxylon glaucum) & 1375.000 & 27.228 & 0.800 & 12.121 & 48.656 \\
4. & Kempas (Koompassia malaccensis Benth) & 75.000 & 1.485 & 0.200 & 3.030 & 6.771 \\
5. & Madang (Litsea sp.) & 200.000 & 3.960 & 0.400 & 6.061 & 14.827 \\
6. & Mahang (Macaranga pruinosa (Miq.) Mull. Arg.) & 200.000 & 3.960 & 0.600 & 9.091 & 18.593 \\
7. & Meranti (Shorea sp.) & 400.000 & 7.921 & 0.400 & 6.061 & 19.002 \\
8. & Mertibu (Dactylocladus stenostachys) & 125.000 & 2.475 & 0.200 & 3.030 & 9.559 \\
9. & Palawan Merah (Tristaniopsis sp.) & 525.000 & 10.396 & 0.800 & 12.121 & 35.282 \\
10. & Punak (Tetramerista glabra) & 950.000 & 18.812 & 0.600 & 9.091 & 36.199 \\
11. & Terantang (Campnosperma coriaceum) & 325.000 & 6.436 & 0.600 & 9.091 & 24.330 \\
12. & Tumih (Combretocarpus rotundatus) & 200.000 & 3.960 & 0.600 & 9.091 & 33.695 \\
13. & Tutup Kabali (Diospyros pseudomalabarica) & 175.000 & 3.465 & 0.400 & 6.061 & 17.760 \\
\hline & $\quad$ Jumlah & 5050 & 100 & 6.6 & 100 & 300 \\
\hline
\end{tabular}

Keterangan:

K : Kerapatan $(\mathrm{K})$

KR : Kerapatan Keralif (KR)

F : Frekuensi (F)

FR : Frekuensi Relatif (FR)

INP : Indeks nilai penting (INP)

Jumlah vegetasi tumbuhan pada lokasi penelitian seperti pada Tabel 4 sebanyak 14 jenis pohon. INP dominan pada jenis pohon Gerunggang dan nilai INP terendah pada pohon Kempas.

Frekuensi relatif (FR) tertinggi terdapat pada jenis Gerunggang dan Palawan Merah serta nilai terendah pada jenis Mertibu dan Kempas. Hal ini menunjukan jenis vegetasi Mertibu dan Kempas tidak 
cocok terhadap areal hutan Kerangas. Sedangkan pada jenis Gerunggang dan Palawan Merah memiliki nilai tertinggi, hal ini menunjukan jenis Gerunggang dan Palawan Merah cocok terhadap areal lingkungan hutan Kerangas, karena pohon tersebut mampu beradaptasi dengan lingkungannya.

\section{Kesimpulan dan Saran}

Kesimpulan penelitian ini yaitu terdapat 23 jenis vegetasi yang ditemukan pada tingkatan Semai, 24 jenis vegetasi yang ditemukan pada tingkatan Pancang, 14 jenis vegetasi yang ditemukan pada tingkatan Tiang, 13 jenis vegetasi yang ditemukan pada tingkatan Pohon, kelima tipe vegetasi/ekosistem hutan di kawasan hutan

Jenis vegetasi Blumeodendron tokbrai memiliki nilai tertinggi dengan nilai NIP 18.047 pada tingkat semai. Jenis vegetasi (Litsea sp.) memiliki nilai tertinggi dengan nilai NIP 18.159 pada tingkat pancang. Jenis vegetasi Syzygium lineatum, memiliki nilai tertinggi dengan nilai NIP 44.584 pada tingkat tiang. Jenis vegetasi Cratoxylon glaucum, memiliki nilai tertinggi dengan nilai NIP 48.656 pada tingkat pohon.

Saran berdasarkan penelitian ini yaitu perlu dikembangkannya jenis vegetasi yang ditemukan pada vegetasi hutan Kerangas di kawasan Arboretum Nyaru Menteng sebagai jenis awal/pioneer dalam upaya pelestarian hutan Kerangas.

\section{Referensi}

[1] Bruenig, EF. 1995. Conservation and Management of Tropical Rain Forest: An Integrated Approached to Sustainability. CAB International.

[2] Whitmore, TC. 1986. Tropical Rainforest of the Far East. 2nd ed. Oxford. Clarendon Press.

[3] Supriatna, Jatna. 2008. Melestarikan Alam Indonesia. Yayasan Obor Indonesia. Jakarta.

[4] Onrizal, 2004. Model Penduga Biomassa dan Karbon Tegakan Hutan Kerangas di Taman Nasional Danau Sentatum Kalimantan Barat. Tesis. Bogor: Sekolah Pasca Sarjana Institut Pertanian Bogor.

[5] MacKinnon, K., Hatta, G., Hakim, H., Mangalik, A. 1996. The Ecology of Kalimantan Indonesian Borneo.The Ecology of Indonesia series III.Periplus Editions (HK) Ltd. 872p.

[6] Wahyudi, T., Panggabean .T.R., \& Pujianto. (Ed). (2008). Panduan Lengkap Kakao : Manajemen Agribisnis dari Hulu Hingga Hulir. Swadaya

[7] Adnan, H., (Ed). (2008). Belajar dari Bungo Mengelola Sumberdaya Alam di Era Desentralisasi. Bogor : Cifor

[8] Rahim, S., \& Baderan., D.W.K. (2017). Hutan Mangrove dan Pemanfaatannya. Sleman : CV. Budi Utama

[9] Fachrul, M. F. 2007. Metode Sampling Bioekologi. Bumi Aksara. Jakarta.

[10] Kusmana, C. 1997. Metode Survey Vegetasi. PT. Penerbit Institut Pertanian Bogor. Bogor.

[11] Setiawan, Heru, 2016, Analisis Vegetasi Kawasan Hutan Adat Lindu Untuk Penilaian Kesehatan Hutan Daerah Penyangga, Prosiding Seminar Nasional from Basic Science to Comprehensive Education, UIN Alauddin Makassar

[12] Bakri. 2009. Analisis Vegetasi Dan Pendugaan Cadangan Karbon Tersimpan Pada Pohon Di Hutan Taman Wisata Alam Taman Eden Desa Sionggang Utara Kecamatan Lumban Julu Kabupaten Toba Samosir . Tesis. Sekolah Pascasarjana. Universitas Sumatera Utara.

[13] Hadi, Etik Erna Wati, Siti Muslimah Widyastuti, Subagus Wahyuono, Keanekaragaman Dan Pemanfaatan Tumbuhan Bawah Pada System Agroforestry Di Perbukitan Menorah, Kabupaten Kulon Progo, Jurnal Manusia dan Lingkungan, vol. 23, no.2, Juli 2016.

[14] Kissinger, Yamani, A., Thamrin, G.A.R., Muhayah, R.N.P., Darusman, L.K., Zuhud, E.A.M. (2013). Keanekaragaman Jenis Tumbuhan Obat Dari Hutan Kerangas. Jurnal Hutan Tropis (1): 1-7

[15] Pamoengkas, Prijanto, Ayi Kulsum Zamzam, komposisi functional species group pada system silvikultur tebang pilih tanam jalur di area IUPHHK-HA PT. SARPATIM, Kalimantan Tengah, Jurnal Sivikultur Tropika, Vol. 08 No. 3, Desember 2017. 